\title{
Modeling and Simulation Research on the Influence of Dynamic Process of EV Charging Station on Transient Voltage Stability of Distribution Network
}

\author{
Wenhuan Hao, Aina Tian,Yiying Gao and Lize Ran \\ Department of Electrical Engineering and Automation, Harbin Institute of Technology, Harbin, Heilongjiang Province, China
}

\begin{abstract}
The promotion of electric vehicles (EVs) has eased the shortage of fossil fuels, but also brings challenges to the grid. Load modeling of EV is an important technical reserve to deal with the challenge. From practical application, this paper built the model of charging system consisting of voltage source PWM rectifier, phase-shift full bridge ZVS DC-DC converter and power battery pack and connected the model built to distribution system containing composite load. Furthermore, the paper calculated the critical clearing time of induction motor and used it as an index to evaluate the transient voltage stability under different EV penetration rate. Then the impact of dynamic characteristics of $\mathrm{EV}$ charging station on transient voltage stability of distribution network and its influence factors was analyzed. The results provided useful information for the safe and stability of power system with large-scaled EV accessed.
\end{abstract}

Keywords-electric vehicle; transient voltage stability; charging station; dynamic model

\section{INTRODUCTION}

With the increasing popularity of vehicles, environmental pollution and energy crisis it bought has become more and more serious. To develop pollution-free EV has important strategic significance to relieve above problems, but EV charging load is of strong random characteristics, and will always superpose existing peak load curve, then increase peak shaving task. As a result, many scholars have done research on the impact of large-scaled charging load on the power grid and the coordinated charging strategy.

Current research on electric vehicle load modeling focuses on the static load model, including the prediction of daily load curve, to analyze the problems of load balance, harmonic pollution, power loss and voltage drop ${ }^{[1]}$, and further to optimize the dispatching a and location, but do little research on the dynamic process. References [2-3] estimated large-scaled EV charging load data according to the survey data and the development law of EVs; [4] studied its effects aiming at specific EV type and application scenario; [5] study voltage sags under different EV penetration rate taking a typical low-voltage distribution network in British as example. On the other hand, EV charging station is a typical power electronic device of large capacity and high current ${ }^{[6-7]}$, which will bring significant impact on transient voltage stability of power system. Induction motor is an important dynamic load in power system, [8] used the critical clearing time of it as an index to reflect the transient voltage stability of the node with induction motor load. Reference [9] proposed a margin index considering induction motor load to study transient voltage stability with large-scaled EV load accessed, but considering EV load as static load.

The paper chose phase-shift full bridge ZVS DC-DC converter and voltage source PWM rectifier, according to the battery parameters of Tesla Model S 85,to build the dynamic model of EV charging station. Critical clearing time of induction motor in composite load is calculated. Then connected the model and composite load to IEEE33 node distribution system simulation case, setting different scenarios, utilizing the critical clearing time calculated before to evaluate the impact of dynamic process of EV charging station on transient voltage stability of distribution network and analyze the influence factors.

\section{Dynamic Simulation Model of EV Charging SYSTEM}

Charging system is the core part of an EV charging station. Common DC bus structure has the advantages of managing power quality of grid side easily and needing fewer rectification devices, and is adopted to established the model in this paper.

\section{A. Power Battery Modeling}

Among many kinds of battery models, equivalent circuit model has explicit physical meaning and is easy for mathematical analysis ${ }^{[0]}$. PNGV model shown below is used in this paper. This model can describe the transient process of batteries and relationship between battery performance and state of charge (SOC).

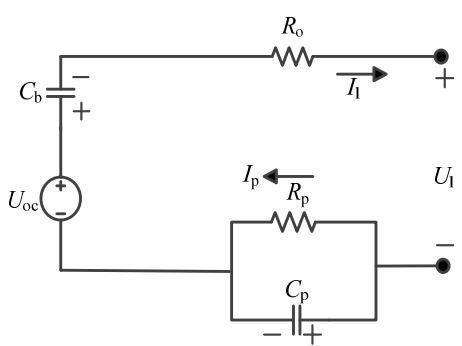

FIGURE I. THE EQUIVALENT CIRCUIT OF PNGV MODEL. 
Discretization equation of this circuit can be obtained as below, and through parameters identification test the circuit parameters could be gained.

$$
U_{1, i}=E-\frac{1}{C_{\mathrm{b}}} \sum\left(I_{1} \Delta t\right)_{i}-R_{\mathrm{o}} I_{1, i}-R_{\mathrm{p}} I_{1, i}
$$

In Tesla Model S battery system, 7623 cells form a battery pack. The circuit model and parameters of the battery pack can be obtained by circuit transformation.

\section{B. DC-DC Converter Modeling}

The main circuit topology of phase-shift full bridge ZVS converter is shown as below.

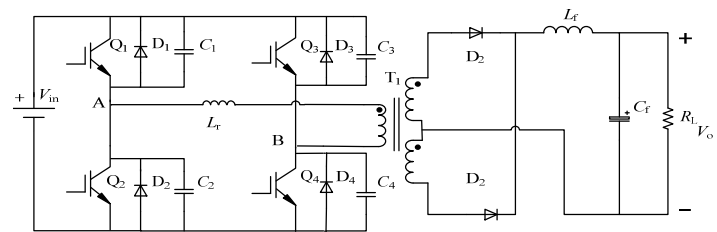

FIGURE II. MAIN CIRCUIT TOPOLOGY OF PHASE-SHIFT FULL BRIDGE ZVS DC-DC CONVERTER.

This topology is chosen for the following considerations: It has isolation transformer, which is safer, can guarantee personal security while charging; it includes four power switches so is suitable for high power value occasions; it can achieve ZVS so reduce switching losses.

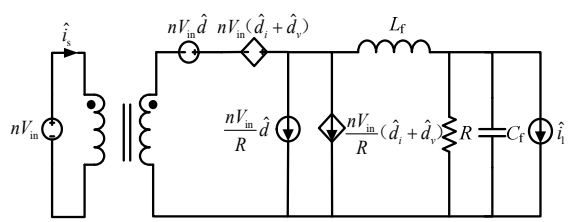

FIGURE III. SMALL SIGNAL MODEL OF PHASE-SHIFT FULL BRIDGE ZVS DC-DC CONVERTER.

Small signal modeling methods of Buck can be used to established the model of phase shifted full bridge converter, which is shown above. Using average current mode, the control block diagram of double loop control method of voltage and current is shown in Figure IV..

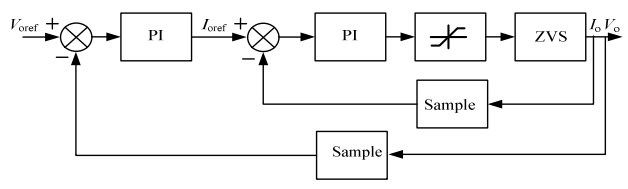

FIGURE IV. CONTROL BLOCK DIAGRAM OF PHASE-SHIFT FULL BRIDGE ZVS DC-DC CONVERTER.

\section{Three-Phase PWM Rectifier}

Compared to thyristor phase controlled rectifier and diode rectifier, PWM rectifier circuit can maintain the power factor approximating to unity through control, so three phase VSR is used in this paper to build the model for the AC-DC part of the charger.
There are two aims of the controller: maintaining the voltage of DC bus; realizing unity power factor operation. Double loop strategy of PI regulator, which is extensively used is adopted. The control block diagram is shown below.

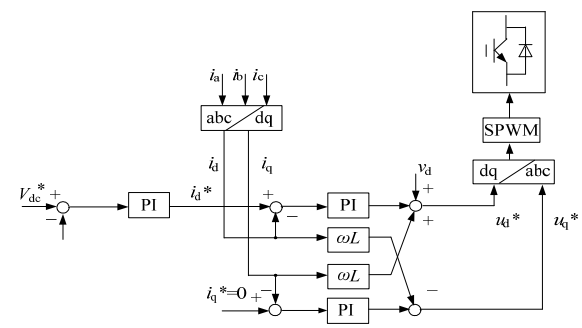

FIGURE V. CONTROL BLOCK DIAGRAM OF THREE PHASE VSR.

\section{TRANSIENT Voltage Stability IndEX CONSIDERING INDUCTION MOTOR}

In composite load model, dynamic behavior of the load is described by parallel static load and induction motor. The equivalent circuit diagram of induction motor is shown in Figure VI.

Figure VII shows a typical mechanical characteristic curve of three phase induction motor. The one of larger value among the intersections of electromagnetic torque and mechanical torque curves after the fault is the unstable equilibrium point, namely the critical clearing slip. The corresponding critical clearing time could represents transient voltage stability.

By T-equivalent circuit of Figure VI., it is easy to get the mechanical torque $T_{\mathrm{e}}$ :

$$
T_{\mathrm{e}}=\frac{R_{2}}{S} \frac{V_{\mathrm{t}}^{2}}{\left(R_{\mathrm{t}}+\frac{R_{2}}{S}\right)^{2}+\left(X_{\mathrm{t}}+X_{2}\right)^{2}}
$$

In which

$$
\begin{gathered}
\dot{V}_{\mathrm{t}}=\frac{Z_{\mathrm{m}}}{Z_{\mathrm{m}}+Z_{1}} \\
R_{\mathrm{t}}+\mathrm{j} X_{\mathrm{t}}=\frac{Z_{\mathrm{m}} Z_{1}}{Z_{\mathrm{m}}+Z_{1}}
\end{gathered}
$$

From above equation, the critical clearing slip could be solved:

$$
S_{\mathrm{c}}=\frac{R_{2}}{2} \frac{V_{\mathrm{t}}^{2}-2 T_{\mathrm{m}} R_{\mathrm{t}}+\sqrt{V_{\mathrm{t}}^{4}-4 V_{\mathrm{t}}^{2} T_{\mathrm{m}} R_{\mathrm{t}}-4 T_{\mathrm{m}}^{2}\left(X_{\mathrm{t}}+X_{2}\right)^{2}}}{T_{\mathrm{m}}\left(R_{\mathrm{t}}^{2}+\left(X_{\mathrm{t}}+X_{2}\right)^{2}\right)}
$$

Corresponding critical clearing time:

$$
t_{\mathrm{c}}=\frac{2 H\left(s_{\mathrm{c}}-s_{0}\right)}{T_{\mathrm{m}}}
$$


In which $s_{0}$ is the initial slip of the motor. In actual dynamic process, there is a period of transient time of the rotor for recovery after the fault is removed, which will have a negative impact on the critical clearing time. When considering the rotor's transient time, the result should be amended as:

$$
t_{\mathrm{cm}}=t_{\mathrm{c}}-\frac{S_{\mathrm{dec}}}{T_{\mathrm{m}}}
$$

In which $S_{\text {dec }}$ is the deceleration area during the transient process, i.e., the area of which the electromagnetic torque is lower than mechanical torque, and it can be obtained by time domain simulation.

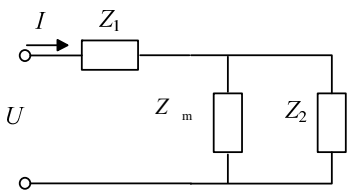

FIGURE VI. EQUIVALENT CIRCUIT OF INDUCTION MOTOR.

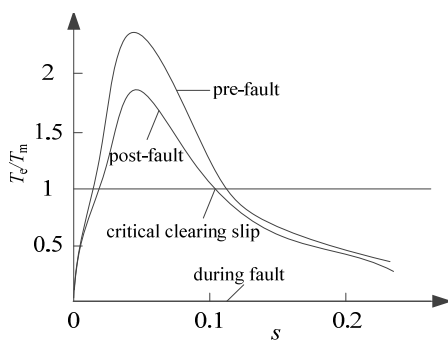

FIGURE VII. TORQUE-SLIP CURVES OF A GENERAL MOTOR.

\section{SIMULATION AND ANALYSIS OF IMPACT OF EV} CHARGING STATION ON TRANSIENT VOLTAGE STABILITY OF DISTRIBUTION NETWORK

\section{A. Simulation Configuration}

Simulation model was built on MATLAB/Simulink platform. Taking lithium battery pack of Tesla Model 85 as an example, its main parameters are shown in the following.

TABLE I. PARAMETERS OF BATTERY PACK IN TESLA MODEL S 85

\begin{tabular}{|c|c|c|c|c|}
\hline $\begin{array}{c}\text { Capaci } \\
\text { ty } \\
\text { (kwh) }\end{array}$ & $\begin{array}{c}\text { Rated } \\
\text { Voltage(V) }\end{array}$ & $\begin{array}{c}\text { Cell } \\
\text { Voltage(V) }\end{array}$ & $\begin{array}{c}\text { Cell Cut-off } \\
\text { Voltage(V) }\end{array}$ & $\begin{array}{c}\text { Cell } \\
\text { Capacit } \\
\mathbf{y} \\
\text { (Ah) }\end{array}$ \\
\hline 85 & 356 & 3.6 & 4.2 & 3.1 \\
\hline
\end{tabular}

The paper adopted constant-voltage limitarycurrent(CVLC) mode and set output voltage of single charging pile to be $416 \mathrm{~V}$, which is the charging cut-off voltage. The other main parameters of the charger model is shown in table II and table III.
TABLE II. MAIN PARAMETERS OF THREE PHASE VOLTAGE SOURCE PWM RECTIFIER

\begin{tabular}{|c|c|c|c|c|}
\hline $\begin{array}{c}\text { Input } \\
\text { Voltage } \\
(\mathbf{k V})\end{array}$ & $\begin{array}{c}\text { DC Bus } \\
\text { Voltage } \\
(\mathbf{V})\end{array}$ & $\begin{array}{c}\text { Capacity } \\
(\mathbf{k W})\end{array}$ & $\begin{array}{c}\text { De Capacitor } \\
(\boldsymbol{\mu} \mathbf{F})\end{array}$ & $\begin{array}{c}\text { Switching } \\
\text { Frequenc } \\
\mathbf{y}(\mathbf{H z})\end{array}$ \\
\hline 0.38 & 650 & 500 & $75000 * 2$ & 1350 \\
\hline
\end{tabular}

TABLE III. MAIN PARAMETERS OF PHASE-SHIFT FULL BRIDGE ZVS DC-DC CONVERTER

\begin{tabular}{|c|c|c|c|c|c|c|}
\hline $\begin{array}{c}\text { Capa } \\
\text { city } \\
(\mathbf{k W})\end{array}$ & $\begin{array}{c}\text { Switch } \\
\text { Freque } \\
\mathbf{n c y} \\
(\mathbf{k H z})\end{array}$ & $\begin{array}{c}\text { Filter } \\
\text { Capaci } \\
\text { tor } \\
\mathbf{( \mu \mathbf { F } )}\end{array}$ & $\begin{array}{c}\text { Filter } \\
\text { Induct } \\
\mathbf{o r} \\
(\boldsymbol{\mu} \mathbf{H})\end{array}$ & $\begin{array}{c}\text { Reson } \\
\text { ant } \\
\text { Capaci } \\
\text { tor } \\
(\mathbf{n F})\end{array}$ & $\begin{array}{c}\text { Reso } \\
\text { nant } \\
\text { Indu } \\
\text { ctor } \\
(\boldsymbol{\mu H})\end{array}$ & $\begin{array}{c}\text { Turns } \\
\text { Ratio }\end{array}$ \\
\hline 35 & 20 & 4500 & 400 & 5 & 9 & 0.87 \\
\hline
\end{tabular}

In IEEE33 node radial distribution network, several representative nodes was selected to access the dynamic model of EV charging station and composite load model, in order to analyze the impact of dynamic process of $\mathrm{EV}$ charging station on transient voltage stability of distribution network and its influence factors.

\section{B. Impact of Different EV Penetration rate on Transient Voltage Stability of Distribution Network}

Set the proportion of induction motor load to be $30 \%$, parameters of which are shown in table IV. When the EV load penetration rate is $25 \%$, the number of EVs charging in every station, whose SOC, charging power and other parameters are shown in table $\mathrm{V}$.

TABLE IV. MAIN PARAMETERS OF INDUCTION MOTORS OF THE LOAD NODES

\begin{tabular}{|c|c|c|c|c|c|c|}
\hline $\begin{array}{c}\text { Steady } \\
\text { Slip } \\
(\mathbf{p u})\end{array}$ & $\begin{array}{c}\boldsymbol{R}_{\mathbf{1}} \\
(\mathbf{p u})\end{array}$ & $\begin{array}{c}\boldsymbol{X}_{\mathbf{1}} \\
(\mathbf{p u})\end{array}$ & $\boldsymbol{R}_{\mathbf{2}}(\mathbf{p u})$ & $\boldsymbol{X}_{\mathbf{2}}(\mathbf{p u})$ & $\boldsymbol{X}_{\boldsymbol{m}}(\mathbf{p u})$ & $\mathbf{2 H ( s )}$ \\
\hline 0.0473 & $\begin{array}{c}0.05 \\
73\end{array}$ & $\begin{array}{c}0.09 \\
3\end{array}$ & 0.0486 & 0.0618 & 2.1153 & 0.2854 \\
\hline
\end{tabular}

TABLE V. PARAMETERS OF EV CHARGING LOAD

\begin{tabular}{|c|c|c|c|c|}
\hline Node & $\begin{array}{c}\text { Numb } \\
\text { er of } \\
\text { EVs }\end{array}$ & $\operatorname{SOC}(\%)$ & $\begin{array}{c}\text { Charging } \\
\text { power }(k W)\end{array}$ & $\begin{array}{c}\text { Total } \\
\text { power(kW) }\end{array}$ \\
\hline \multirow{2}{*}{2} & \multirow{2}{*}{2} & 85 & 15 & \multirow{2}{*}{25} \\
\hline & & 90 & 10 & \\
\hline 3 & 1 & 66 & 22.5 & 22.5 \\
\hline \multirow{2}{*}{4} & \multirow{2}{*}{2} & 82 & 17.4 & \multirow{2}{*}{30} \\
\hline & & 90 & 12.6 & \\
\hline \multirow{3}{*}{7} & \multirow{3}{*}{3} & 89 & 10 & \multirow{3}{*}{50} \\
\hline & & 76 & 20 & \\
\hline & & 79 & 20 & \\
\hline 14 & 1 & 12 & 30 & 30 \\
\hline 18 & 1 & 69 & 22.5 & 22.5 \\
\hline \multirow{4}{*}{25} & \multirow{4}{*}{4} & 12 & 30 & \multirow{4}{*}{105} \\
\hline & & 58 & 25 & \\
\hline & & 15 & 30 & \\
\hline & & 79 & 20 & \\
\hline 33 & 1 & 85 & 15 & 15 \\
\hline
\end{tabular}

Set the fault at the outlet of the source(node 1),from $0.6 \mathrm{~s}$ to 0.7 s.Taking node 2 as an example, When the EV load penetration rate is $50 \%$ and $25 \%$, voltage curve of the load bus and slip curve of the induction motor is shown in Figure VIII. 

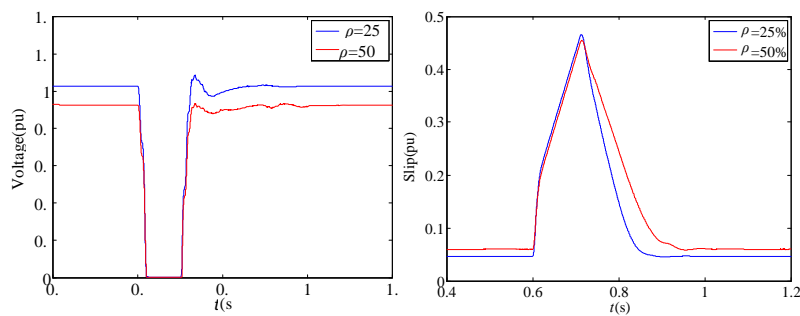

FIGURE VIII. VOLTAGE AND INDUCTION MOTOR'S SLIP CHANGE TENDENCY OF NODE 2 DURING SHORT CIRCUIT

It can be seen that with the increase of $\mathrm{EV}$ load penetration rate, the recovery speed of the bus voltage is slowed down, which is against the stability of voltage. In the following, the critical clearing time will be used as an index to evaluate the transient voltage stability of each node quantitatively. Calculation results are shown as below.

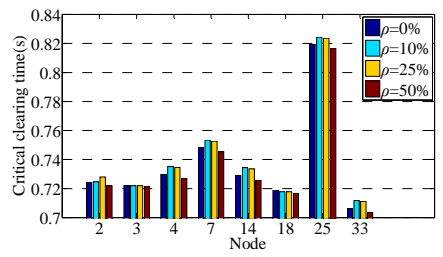

FIGURE IX. COMPARISON OF CRITICAL CLEARING TIME UNDER DIFFERENT EV LOAD PENETRATION RATE.

Obviously, as EV penetration rate increases, the transient voltage stability level of the nodes first increases and then decreases. While the penetration rate is small, compared with the scenario without EV load, the transient voltage stability level slightly improves. This point is more evident in the nodes with load of higher value. The nodes containing less load(node 2) almost remains even, while the nodes with lowest load level $(3,18)$ did not even rises.

The reason is that after the clearing of the fault, rapid response ability of the rectifier played a certain role in promoting voltage recovery. Figure $\mathrm{X}(\mathrm{A})$ shows that after clearing the fault at $0.7 \mathrm{~s}$, reactive power of the rectifier is negative in the recovery process, so that the bus voltage is improved, by(2), voltage $V_{\mathrm{t}}$ is proportional to electromagnetic power $T_{\mathrm{e}}$, which therefore increases the acceleration area and improves the critical clearing time. However, the adjustment capacity of the rectifier is limited, while the penetration rate continues to increase, the critical clearing time will begin to reduce.

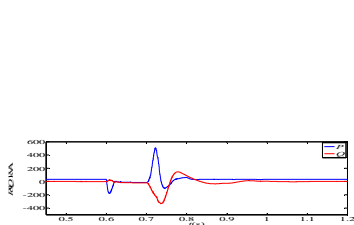

(A)

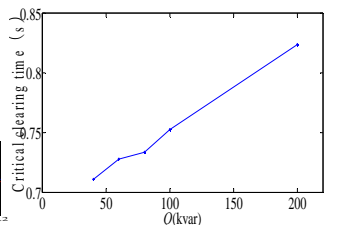

(B)
FIGURE $X$. SIMULATION RESULTS UNDER EV PENETRATION RATE OF 25\%: (A)ACTIVE \& REACTIVE POWER CURVE OF NODE 25. (B) INDUCTION MOTOR'S SLIP CHANGE TENDENCY WITH THE CHANGE OF REACTIVE POWER CAPACITY.

\section{Influence Factors Analysis}

1) The distance from the root node: As can be seen from Figure IX, node 4, 14 and node 3, 18, respectively have the same value of load, under each penetration rate, the nodes further from the source,i.e. 14,18 has smaller critical clearing time.

2) Reactive power capacity of each node: Taking EV penetration rate of $25 \%$ as an example, it can be seen from Figure $\mathrm{X}(\mathrm{B})$ obviously that for a node, the higher the reactive power capacity is, the higher the transient voltage stability is, the smaller the impact EV charging stations dynamic characteristics could bring.

\section{CONCLUSION}

The simulation results showed that: with low EV load penetration rate, the rectifier can quickly respond to generate reactive power, transient voltage stability would slightly increase relative to that of no EV load accessed, which is more evident in the nodes with load of higher value. However, when the penetration rate reaches higher, EV charging load begins to have a negative impact on transient voltage stability. By Comparing each access node, it can be found that the impact of charging station dynamic process on transient voltage stability has much to do with reactive power capacity of the access node and the distance from the source, which should be paid enough attention to in charging station site selection and construction. Combining the probability nature of EV charging distribution to study the dynamic characteristics of charging stations, will be the direction of further studies.

\section{REFERENCES}

[1] Gao Ciwei, Zhang Liang, "A Survey of Influence of electrics vehicle Charging on Power Grid,” Power System Technology.Beijing, vol. 35(2), pp.127-131, Feburuery 2011.

[2] Luo Zhuowei, Hu Zechun, Song Yonghua, "Calculation method of electric vehicle charging load”, Automation of Electric Power Systems.Nanjing, vol. 35(14) , pp.36-42, July 2011.

[3] Luo Zhuowei, Hu Zechun, Song Yonghua, "Study on charging load modeling and coordinated charging of electric vehicles under battery swapping modes," Proceedings of the CSEE.Beijing, vol.32(31), pp.1-10,November 2012.

[4] Kristien C N,Edwin H,Johan D, “The impact of charging plug-in hybrid electric vehicles on a residential distribution grid,” IEEE Trans on Power Systems. vol.25(1),pp. 371-380,2010.

[5] P Papadopoulos, L M Cipcigan,N Jenkins, "Distribution Networks with Electric Vehicles, ”Universities Power Engineering Conference (UPEC).Glasgow,England,2009.

[6] Schneider K,Gerkensmeyer C,Kintner-Meyer M, “Impact assessment of plug-in hybrid vehicles on pacific northwest distribution systems, "Power and Energy Society General Meeting-Conversion and Delivery of Electrical Energy in the 21st Century.Pittsburgh, PA ,2008.

[7] Hu Zechun,Song Yonghua,Xu Zhiwei, "Impacts andutilization of electric vehicles integration into power systems," Proceedings of the CSEE.Beijing, vol. 32(4), pp. 10-25,February 2012.

[8] Li Lili,Lu Chao, C.K.Wong, "Analytical assessment of transient voltage stability of load bus consideing induction motors," Automation of Electric Power Systems.Nanjing, vol.33(7), pp. 15,April 2009.

[9] Yanxia Chen, Peiwen Zheng, "Study on the influence of large-scaled electric vehicle dispersed charging on transient voltage stability of 
distribution systems,"Asia-Pacific Power and Energy Engineering Conference (APPEEC).Hong Kong,China,2014.

[10] Ta La, "Research on electric vehicle traction battery modelling simulation and life cycle performance,” Beijing: Tsinghua University, 2011, pp.68-73. 